\title{
Seguridad ciudadana y transformación del sistema de justicia penal nicaragüense
}

Sergio J. Cuarezma Terán*

Resumen.- La seguridad ciudadana, el equilibrio y la consolidación del Estado democrático y social de derecho, se fundamenta en la estabilidad y coherencia del orden jurídico, en la internalización del mismo por el ciudadano y por el propio poder, y en la transformación de la cultura jurídica de la comunidad. La seguridad ciudadana debe conjugar no sólo la vigencia formal del derecho y comprender la seguridad personal y patrimonial de las personas, sino también el derecho que tienen las personas a gozar de la vigencia real y efectiva de un Estado de derecho constitucional y de un estándar mínimo o razonable de bienestar de salud, educación, vivienda e ingreso.

\section{Introducción}

El marco de definición de la Constitución de Nicaragua no se agota en los derechos, libertades y garantías, sino que deja abierto el camino para adecuar el funcionamiento de las instituciones a principios y valores que garanticen la dignidad de la persona. En este sentido debe enfocarse la responsabilidad que tanto el Estado como la sociedad tienen en materia de seguridad del habitante, prevención y control del delito.

Uno de los aspectos que conspiran contra la paz social es la inseguridad del habitante (o ciudadana). Esta es el resultado de un aumento en la criminalidad, que afecta las condiciones de vida de la población. La ineficacia en la prevención y el cońtrol de la criminalidad se debe, entre otras cosas, a la inexistencia de un programa nacional de política criminal con objetivos realistas.

El Estado (con su aparato represivo) no ha podido controlar el alto índice delictivo, ya que su actuación no logra incidir en las causas que originan y condicionan la explosión delictiva, debido a que no ha estudiado ni investigado con seriedad la extensión y características de la criminalidad. No la conoce y, por lo tanto, carece de estrategias de lucha contra la misma, lo cual hace que cualquier acción contra ella sea errática e ineficaz. Por el contrario, se concentra en respuestas represivas (dispersas y graves) que afectan fundamentalmente a los sectores socio-económicos más débiles. La solución de este problema requiere abarcar los aspectos preventivos, tanto como los propiamente represivos en sus expresiones convencionales, no convencionales y de violencia doméstica.

\section{La verdadera prevención: antes del delito}

No es aconsejable limitar las respuestas a los problemas sociales con medidas de carácter represivo o punitivo, antes al contrario, habría que promover otras formas "positivas", no sancionadoras o violentas, de resolución de conflictos.

* Profesor de la Facultad de Ciencias Jurídicas -UCA. 
Además, si realmente deseamos "prevenir" el delito, habrá que recordar que la acción de la justicia penal es exclusivamente a posteriori del delito. No podemos seguir reaccionando sólo luego de los hechos y por medio del sistema de justicia penal, sino con políticas integrales, que incorporen acciones para prevenir el delito en el significado etimológico de la palabra. Esto es, para evitarlo.

La prevención de la criminalidad debe contemplar la "prevención social", que consiste en acciones dirigidas a atacar las raíces profundas del delito en la población general o en grupos especialmente vulnerables. La "prevención situacional", se dirige principalmente a reducir las oportunidades del delito, partiendo de la observación criminológica de que determinados delitos se cometen con mayor frecuencia en determinadas situaciones. Y la "prevención por medio de la comunidad", toma y combina medidas de prevención de las anteriores, llevándola a la práctica en el contexto comunitario.

El aparato del Estado no puede prevenir y controlar por sí sólo el alto índice delictivo, y las comunidades están jugando un rol pasivo frente a él. Si estas últimas no contribuyen al control de la criminalidad, no se modificará la situación actual. Por el contrario, es de prever una agudización de las conductas graves o nocivas, las cuales pueden constituirse en un factor de desestabilización en una situación de crisis.

Tomando en cuenta la extensión del fenómeno y su importancia económica, política y social, el Estado y la sociedad civil requieren coordinar sus recursos para crear un sistema de educación y participación ciudadana en el área de prevención de la criminalidad. Para ello es indispensable contar con indicadores confiables y generar técnicas sociales de prevención, sustentadas en estudios científicos sobre el particular. En este tema el Municipio juega un papel fundamental.

\section{Crisis y transformación del sistema de justicia penal}

El sistema de justicia penal se ve impotente para controlar y solucionar de forma efectiva dicha problemática, ya que sus códigos y leyes se encuentran francamente desactualizados frente a las necesidades actuales. En la mayoría de los casos, carecen de vigencia y autenticidad social, y los operadores de las agencias penales carecen de la preparación técnica y científica indispensable para abordar la situación.

En este sentido, el sistema de justicia penal nicaragüense debe experimentar cambios significativos de manera rápi$\mathrm{da}$, antes de que la predicciones pesimistas de un derrumbamiento total del sistema se vuelva una realidad. Hay quienes niegan la necesidad de cambio, creando la ilusión de que castigos más drásticos y más prisiones serán suficientes para estabilizar nuestra sociedad durante estos tiempos críticos. La verdad es que la reforma de estas instituciones se hace inaplazable. Si los esfuerzos de reforma y renovación no son prontos y exitosos, otras instituciones democráticas tal vez no sobrevivan.

\section{La reforma del Código Penal}

El Código Penal vigente del primero de abril de 1974 que, con ciertas modificaciones y novedades, es el mismo de 1879 y 1891 , tiene como fuente inmediata el Código español de 1870.

El código penal representa el grado de civilización que un país ha logrado 
alcanzar, tanto por el tipo y funciones de penas que contiene como por la selección de los objetos a proteger de forma máxima. Cuando un código penal se crea o se reforma, hay cuestiones de fondo que deben determinarse con toda claridad: si los bienes objetos que se tutelan merecen protección, si el comportamiento que se castiga merece la sanción penal y si ésta es la única o última de las medidas contra el acto que se reprueba. Las respuestas a dichas preguntas sólo pueden hacerse en el marco de un Estado democrático y social de derecho, para que tengan un alto contenido ético, ya que no solamente se trata de castigar, sino de recuperar y reinsertar al delincuente en la sociedad con todo tipo de garantías procesales penales, lo cual sólo es posible en un Estado que a priori, reconozca y respete los derechos económicos, sociales y culturales.

Una reforma penal debe contar con un estudio previo que fundamente la prevención y control del delito, la atención a las víctimas del delito, la definición de garantías procesales claras, el tipo y función de pena y la variedad de medidas alternativas a la privación de libertad, y la clasificación y tratamiento de los condenados. Lamentablemente, el país no cuenta con un diseño de política criminal, lo cual nos obliga a ser prudentes en la forma de seleccionar los comportamientos a castigar, las cosas u objetos a proteger y las formas de reprimir.

La evolución o vertebración civil de la sociedad nicaragüense ha sido vertiginosa, al punto de que hoy día existe un cúmulo importante de reivindicaciones. Por ejemplo, un nuevo código penal debería formular y fortalecer las garantías a la persona y crear, conforme la sensibilidad social y el desarrollo tecnológico y científico actual, delitos cuyos comportamientos actualmente son impunes: lesiones al feto, manipulación genética, la reproducción asistida sin el consentimiento de la mujer, la tortura, la omisión del deber de socorro, el abandono o incumplimiento de los deberes hacia la familia, la protección del patrimonio nacional, delitos de tráfico de influencia y corrupción; de las defraudaciones del fluido eléctrico y de agua; de los delitos contra la propiedad intelectual, delitos utilizando los medios informáticos, delitos contra el medio ambiente, contra la seguridad del tráfico.

Estas reformas no pueden ser elaboradas a espaldas de los criterios y sensibilidad jurídica del resto de los países de la región centroamericana $y$, mucho menos, cerrando los ojos a una innegable realidad que afectará dicha reforma: la globalización. En este sentido, es indispensable definir de forma consensuada el "modelo" penal y procesal penal, constitucional, social y científico que establecerá la futura legislación penal de los próximos cien o doscientos años.

\section{El proceso penal vigente: características}

La legislación procesal penal vigente del 29 de marzo de 1879 , está fundamentada en la ideología del juicio inquisitivo del año 1500 . La investigación es secreta; el proceso es burocrático y despersonalizado y escrito; la mayoría de las pruebas para acusar o absolver a una persona se producen en la etapa secreta (en la etapa instructiva); las víctimas o acusados prácticamente no ven nunca al juez; la figura del juez constitucional es suplantada por la figura del secretario; el procurador penal es un agente pasivo y un simple dictaminador de las pruebas que recolecta el juez inquisitivo. El proceso es inquisitivo, lo cual involucra afectivamente al juez en la investigación formándose éste una opinión antes de dictar sentencia, y por tanto, pierde su 
imparcialidad ante los hechos. La víctima carece de derechos y de la protección respectiva, es marginada y relegada al plano secundario de un espectador; la culpabilidad o falta de culpabilidad se decide en el sumario informativo o primeras diligencias de instrucción; y la víctima y el acusado son llevados a un jurado que, por cierto, no tiene previamente una concepción segura de los hechos sobre los que le toca emitir veredicto de inocencia y culpabilidad. Todo ello vulnera las garantías del debido proceso establecidas en la Constitución Política (Art. 34).

\section{El nuevo proceso penal}

El modelo procesal penal nicaragüense se encuentra agotado. Vive horas extras y afecta los derechos constitucionales del debido proceso de la víctima y del acusado.

El Estado nicaragüense ha reconocido esta grave situación y se prepara para su reforma. Hay que destacar la voluntad inequívoca de transformación de las instituciones que integran la justicia penal del país (Procuraduría General de Justicia, Policía Nacional, Poder Judicial y Sistema Penitenciario). Puede advertirse una clara decisión política del poder legislativo en garantizar esta reforma que augura en el seno de la Asamblea Nacional una aprobación exitosa, sin perjuicio de los intensos debates que ello, lógicamente, originará. Es tarea de todos fortalecer esa voluntad de los integrantes del sistema para que sea sostenible y llegue a cristalizarse pronto en la transformación real y efectiva de sus instituciones tanto en el ámbito formal como en el material.

En el nuevo modelo procesal existirá una Fiscalía General (independiente y separada de la actual Procuraduría General de Justicia, que funciona como asesor del ejecutivo), que llevará de la mano con la policía la investigación de los delitos, y defenderá gratuitamente los intereses de las víctimas y, cuando corresponda, procederá a la acusación penal. También existirá la defensoría pública que protegerá los intereses de los acusados que no tengan recursos económicos para procurarse una asistencia legal particular verdadera conforme lo estipula la Constitución Política. Habrá un verdadero proceso de carácter oral y público, donde la sentencia se conocerá a la brevedad y las partes se enfrentarán con igualdad de derechos, oportunidades y garantías. Y la víctima del delito recobrará su verdadero rol en el proceso penal. Es decir, un nuevo modelo procesal que tendrá como norte invariable el respeto de los derechos humanos.

\section{Los principios que deberian inspirar la reforma}

La reforma deberá garantizar a todos los habitantes del país una justicia participativa, integral, accesible, independiente, pronta, equitativa, idónea, responsable, autónoma, imparcial, confiable, continua, respetuosa y garante de la dignidad humana. Por ejemplo, se debe garantizar que la reforma sea integral, es decir, que desarrolle una estrategia global de reforma legislativa y administrativa que abarque todos los componentes del sistema de administración de justicia: Procuraduría General de Justicia, Poder Judicial, Sistema Penitenciario y Policía Nacional.

Tal estrategia también incumbe a la Asamblea Nacional, responsable natural de que las reformas se adecuen de acuerdo a las garantías constitucionales relativas al debido proceso $y$ al funcionamiento del sistema de adminis- 
tración de justicia, y a las necesidades reales y culturales del país.

La reforma procesal penal deberá estar fundamentada en el llamado proceso legal o debido proceso que significa derecho a un juicio equitativo, a que los hechos sean vistos públicamente y en un plazo razonable, a que la causa sea vista por un tribunal independiente, imparcial y establecido por la ley, al derecho a ser procesado por un juez (y no por un "secretario"), el derecho a la presunción de inocencia y la fianza, a disponer de tiempo, de facilidades y medios reales para la defensa. En definitiva, al irrestricto respeto de los derechos de la víctima y del acusado.

\section{La Procuraduría General de Justicia como ministerio público: su transformación}

La Procuraduría General de Justicia actualmente aparece jugando varios papeles. Su legalidad le da tres mandatos: 1) Asesor del Estado (Procuraduría General, propiamente dicha); 2) Representante de los intereses de la sociedad víctima del delito (Ministerio Público o Fiscalía General, denominada actualmente Procuraduría Penal Nacional) y 3) Diseñador de las políticas públicas de justicia del Estado (Ministerio de Justicia). Estas "tres personas" en una sola institución limitan el desarrollo de sus funciones, ya que no puede desempeñar sus atribuciones sin que éstas entren en conflicto de intereses $\mathrm{y}$, además, crea una percepción poco clara de su quehacer frente al resto de las instituciones del Estado, la sociedad y la cooperación internacional.

Conforme a su Ley Orgánica, el Ministerio Público es garante de la legalidad y en el sistema procesal mixto (denuncia/acusación) es un investigador.
Sin embargo, no hace ni uno ni lo otro. $\mathrm{Su}$ pasividad no es casual. Es producto de un modelo de proceso inquisitivo, pues quien realiza la actividad de investigación de los hechos penales no es ni la procuraduría ni la policía, sino el juez inquisitivo. La figura del juez investigador castra toda posibilidad de que las partes en el proceso (el procurador penal $\mathrm{y}$ el defensor) puedan desarrollar su respectivo trabajo e impide al propio juez que sea un juez natural e imparcial ante ellas. La arquitectura procesal inquisitiva convierte al procurador penal en un dictaminador de las evidencias que el juez recoge, y la policía aparece como un auxiliar de investigación del Juez. Por tal razón, y a pesar de grandes esfuerzos realizados, la participación de la procuraduría penal como el Ministerio Público en la etapa de investigación, es ocasional y pobre. Su papel está condicionado a la importancia y gravedad de los hechos que se investigan. Y es aún menos visible cuando trata de perseguir actos de corrupción cometidos por funcionarios o empleados públicos del Estado, ya que tiene la obligación por la Ley de brindarles su servicio de representante. Acusar a quien representa o defender a quien tiene que acusar, $¡ \sin$ duda todo un dilema!

Por ello, es muy saludable la decisión de transformar la institución en una Procuraduría que dependa del Ejecutivo como su Asesor, y una Fiscalía General independiente (nombrada por la Asamblea Nacional) que defienda los intereses del pueblo contra el delito, sea cual fuese la naturaleza delictiva de la acción realizada.

Estas reformas se deben desarrollar a partir del nuevo rol que el Ministerio debe jugar de forma separada, frente al Estado y a la sociedad víctima del crimen, y por ende en el proceso penal moderno. Una de las modificaciones 
más importantes que deberá introducirse en la reforma procesal penal (de adultos) es la desaparición del rol tradicional que ha venido cumpliendo el juez de instrucción, ya que esta práctica lesiona los principios básicos de oralidad e inmediación y el derecho a tener juez natural.

Esta grave deficiencia se corrige al asignarle la investigación preliminar al Fiscal o Procurador Penal, quien debe recabar ágil e informalmente los detalles de hecho, así como las pruebas que acreditan la acusación. La investigación preliminar del fiscal fortalece, además de la jurisdicción, los principios de oralidad y el de justicia pronta y cumplida.

El Ministerio Público es el puente que une la acción policial con la función jurisdiccional. La investigación criminal no puede ser supervisada por la autoridad jurisdiccional, sino por el Fiscal en coordinación con la Policía Nacional. También el rescate de la víctima del delito como usuario del Ministerio Público, debe representar uno de los ejes de la reforma, ya que fortalece el principio de tutela efectiva, que pretende que el ente acusador asuma realmente la defensa de los intereses de la víctima $u$ ofendido del crimen, y le preste el servicio debido (representación, asesoría, asistencia, protección, etc.).

El papel estratégico del Ministerio Público en la reforma del Estado es el de asumir la tarea de acusador, sin reproducir los vicios del sistema inquisitivo. La transformación del Ministerio Público no puede ser un hecho aislado, sino parte integral de la transformación de la justicia penal.

\section{Transformación del sistema penitenciario}

La crisis penitenciaria no puede analizarse aisladamente, por cuanto es sólo un eslabón al final del sistema de justicia penal, sistema que exhibe un gran sesgo en su accionar criminalizando desproporcionadamente a las personas más vulnerables y con menor poder. Esta manera de accionar se ve agravada en la actualidad por los grandes volúmenes de población que se encuentran bajo los niveles de pobreza.

El Estado y la sociedad deben generar y apoyar las reformas necesarias para que dentro de los mecanismos constitucionales y democráticos, el país pueda mantener la dimensión y operatividad de sus sistemas penales dentro de límites racionales. Es importante no sobrepasar el número de presos que puedan ser custodiados en condiciones dignas y contemplar la posibilidad de formas no punitiva de resolución de conflictos en las reformas penales y procesales penales. Hay que limitar el uso de la prisión preventiva e introducir una gama de sanciones no carcelarias que brinde a los jueces un amplio abanico de posibilidades para resolver los casos de la justicia penal.

Con algunas excepciones, el panorama penitenciario latinoamericano, presenta una situación claramente insatisfactoria e inadmisible, tanto en lo atinente a sus objetivos y a su organización, como en lo que respecta a los establecimientos penales, a la población reclusa, al personal penitenciario, a los programas de rehabilitación y al respeto de los derechos humanos de los internos. En la mayoría de los países de la región, el sistema penitenciario constituye uno de los sectores más deficientes del sistema penal. 
Dentro de los temas penitenciarios, el subtema de "los presos sin condena" es el más alarmante, por cuanto se trata de presos que no han sido formalmente condenados, pero que están cumpliendo materialmente una condena. No cambia las cosas el hecho de que un gran número de ellos será posteriormente declarado inocente (sobreseidos o absueltos).

Los presos sin condena están teóricamente amparados por el principio de culpabilidad (nulla poena sine culpa), que significa que la pena sólo puede fundarse en la constatación de que puede reprocharse el hecho a su autor, y por la garantía procesal del principio de inocencia, que significa que el estado de inocencia perdura mientras no se declare la culpabilidad.

Ante este panorama, las autoridades de los sistemas penitenciarios de la región en distintos foros naciones e internacionales se han manifestado para expresar su preocupación e indicar posibles estrategias para la solución real de la crisis penitenciaria.

En el I Congreso Iberoamericano de Administración Penitenciaria celebrado en Cartagena de India, Colombia, del 27 de noviembre al 1 de diciembre de 1995 , se propuso entre los Principios Mínimos Comunes, que la actividad carcelaria se ejercerá respetando la personalidad y dignidad de los reclusos. Estos tendrán, como mínimo, el derecho a que la administración penitenciaria respete su dignidad y vele por sus vidas, integridad y salud; derecho al tratamiento penitenciario, a la formación y desarrollo personal, y a su propia emancipación; derecho a formular peticiones y quejas ante las autoridades habilitadas legalmente para controlar la actividad carcelaria y que el ingreso de una persona en un centro penitenciario se efectúe sólo me- diante una orden de la autoridad respectiva; derecho a que el régimen de ejecución se planeará individualmente para cada recluso; derecho a mantener contacto periódico con el exterior y que la estancia en prisión deberá ir orientada a actividades educativas, laborales, culturales y deportivas.

El Congreso insta a los gobiernos a desarrollar políticas globales de inversión en estructuras penitenciarias, para modernizar las instalaciones actuales y a adoptar medidas judiciales con el objetivo de lograr una disminución significativa de las tasas de presos preventivos y políticas globales de formación y capacitación permanente del personal penitenciario, configurando carreras técnicas y profesionales remuneradas adecuadamente.

Por su parte, el seminario "Justicia Penal: el reto de la sobrepoblación penitenciaria" del Programa Sistema Penal y Derechos Humanos, LANUD/Comisión Europea, realizado en San José, Costa Rica, del 3 al 7 de febrero de 1997, expresó que la situación de los sistemas penitenciarios de los países de la región es preocupante y de extrema gravedad. Consideró particularmente alarmante que la tasas de población penitenciaria de los países de la región vengan creciendo aceleradamente durante los últimos cinco años, y que dicho crecimiento no sea necesariamente correlativo al aumento de criminalidad grave.

El seminario propuso promover las reformas necesarias para que en el marco de los mecanismos constitucionales y democráticos, los Estados puedan mantener la dimensión y operatividad de sus sistemas penales dentro de límites racionales y para que no superen el número de presos que puedan custodiar en condiciones dignas y promover la reforma de las Leyes penales y proce- 
sales introduciendo la posibilidad de forma no punitiva de resolución de conflictos. Se recomendó limitar el uso de la prisión preventiva e introducir una amplia gama de opciones no carcelarias, además de la implementación de políticas sociales que aseguren la reinserción social del infractor o infractora.

El Consejo Centroamericano de Procuradores de los Derechos Humanos, reunidos en el marco del referido Seminario, emitió una declaración respecto a la situación de los Sistemas Penitenciarios en cuyas partes más esenciales denuncia la repetida violación de los derechos humanos de las personas privadas de libertad en los centros penitenciarios de la región. El consejo consideró el hacinamiento como una grave violación a los derechos humanos de las personas privadas de libertad, que aumenta las ya precarias condiciones en materia de salud, higiene y alimentación, que existen en los Sistemas Penitenciarios, en abierta contradicción con las Reglas Mínimas de las Naciones Unidas para el Tratamiento de los Reclusos y otros Instrumentos Internacionales relacionados.

La fundamentación legal del sistema penitenciario nicaragüense está cimentada en una serie de leyes, decretos ejecutivos y disposiciones administrativas de naturaleza decimonónica $\mathrm{y}$, en muchos casos, contrarias al modelo constitucional penitenciario vigente. Además, se presenta de forma atomizada y fragmentada.

Basta, por ejemplo, echar un vistazo al ordenamiento administrativo penitenciario para apreciar lo anacrónico y disperso del mismo: Reglamento para las cárceles de la ciudad de Managua (1879); Reglamento para las Penitenciarías de Managua (1901); Reglamento interno para las cárceles y casas de corrección de mujeres (1919); Reglamento para el gobierno y disciplina de las cárceles penitenciarias de la guardia nacional (1929), reformado en 1943 y mejorado en un Código Jurídico Militar (1949); Ley de Patronato Nacionales y departamentales de reos (1946), y su reglamento(1947), reformado en 1948; y por último, las Normas y Procedimientos de control, educación y seguridad penal de 1987.

El Sistema Penitenciario nicaragüense carece de una Ley Orgánica que organice y estructure la institución formal y materialmente $\mathrm{y}$, asimismo, carece de una Ley de Ejecución penal que garantice la legalidad de la ejecución de la sanción conforme a las resoluciones judiciales y a las normas penales sustantivas. El Sistema no cuenta tampoco con una Ley de carrera penitenciaria y de una política penitenciaria que desarrolle el modelo constitucional de la función de la ejecución de la pena, la promoción de programas de rehabilitación dirigidos a la reinserción social del interno.

\section{La justicia penal: un sistema integral}

La justicia penal es, precisamente, un sistema integrado por legislación, policía, fiscalía, justicia y penitenciarías (podrían agregarse otros elementos, pero estos cinco son los "básicos" en una definición clásica del sistema de justicia penal). Por esta razón, la mayoría de los problemas de cada subsistema no tiene posibilidad de solución si se abordan separadamente de los otros subsistemas. La única manera de resolverlos es buscando la respuesta en los otros subsistemas y en el sistema global. Si la transformación del sistema de justicia penal no se realiza de "forma integral y acompañada por todas las instituciones involucradas", se correrá el riesgo de 
que la reforma a pesar de que se haga, se malogre.

\section{La seguridad del habitante como manifestación cultural}

La seguridad de los habitantes, el equilibrio y la consolidación del Estado democrático y social de derecho en Nicaragua, se fundamenta en la estabilidad del orden jurídico, en la interiorización de dicho ordenamiento por el propio sistema, y en la transformación de la cultura jurídica de su comunidad. Este último aspecto es importante para la concepción de una reforma legal penal, ya que la misma no puede ser percibida tan sólo como una secuencia de transformaciones formales de códigos y leyes, sino como un esfuerzo orgánico, integrado y continuo de cambios sociales, que ha de tener como premisa y resultado una transformación cultural de gran dimensión.

La inseguridad del habitante no es solamente un problema derivado del incremento de delitos, de la calidad, vigencia o no del ordenamiento jurídico penal o de las condiciones materiales del Estado, sino también producto de una cultura asumida por la propia sociedad.

$\mathrm{La}$ inseguridad del habitante debe abordarse también desde el punto de vista cultural basado en el comportamiento social. Las violaciones de los derechos de las personas se producen a pesar de la existencia de garantías suficientes en el ordenamiento jurídico. Ese comportamiento ilegal responde a una cultura en donde el Estado de derecho no es un valor fundamental. Debe implantarse el Estado de derecho como un valor social, para lo cual hay que incidir sobre los mecanismos de reproducción social de los valores y sobre el proceso de internalización de forma individual.
La formación dentro del núcleo familiar y la educación institucional de las personas es la vía idónea para la formación de valores sociales que permitan condiciones óptimas para la seguridad del habitante.

\section{Propuestas para la formulación de estrategias que garanticen la seguridad ciudadana}

El concepto de seguridad del habitante (o ciudadana) debe comprender no sólo la seguridad personal y patrimonial, sino también la seguridad jurídica en el cumplimiento de la ley, posibilitando la coherencia del ordenamiento jurídico y la consolidación del desarrollo humano sostenible.

Debería incluir no sólo la seguridad de no ser víctima de delitos, sino también la de gozar de la vigencia de un Estado constitucional de derecho, y de un estándar mínimo o razonable de bienestar en materia de salud, de educación, de vivienda e ingreso. Este concepto sería el de desarrollo humano sostenible que tiene a la equidad como principio. Debería ampliar las oportunidades de las personas para que puedan satisfacer sus necesidades básicas en un clima de convivencia, libre de todo peligro, daño o riesgo a su vida, integridad física o a su patrimonio. Esa libertad sería lo que se puede calificar como seguridad, siendo el Estado el responsable de garantizarla a través de sus instituciones, para evitar lo que el PNUD califica como "perfil de sufrimiento humano". Deben promoverse políticas más efectivas e integrales frente al delito, y no continuar reaccionando solamente a posteriori por medio de los sistemas de justicia penal. Las políticas deberían comprender una amplia prevención primaria, con acciones en todos los ámbitos del bienestar social. 
La niñez y adolescencia son sectores de la población especialmente vulnerables. Por ello urge dirigir los esfuerzos políticos y económicos a garantizar la entrada en vigencia del Código de la Niñez y la Adolescencia.

Las comunidades y los municipios son los que están más cerca de los problemas y están también en la mejor posición para participar activamente en su resolución. Es importante proveer apoyo y capacitación a las municipalidades para desarrollar programas que contribuyan a la reducción de la violencia y a la construcción de comunidades más seguras.

Hay que mantener un equilibrio adecuado de los subsistemas (policial, fiscalía o procuraduría penal, judicial y penitenciaria) que asegure una adecuada relación funcionario-número de habitantes para cada una de ellos, así como la coordinación de la labor y la formación interdisciplinaria de los operadores de dichos sectores.

Un punto fundamental es la incorporación de la víctima del delito a su correspondiente papel procesal, el que, en general, no se le ha reconocido. Asimismo, es vital la organización de sistemas de atención para los infractores.

Es necesaria la creación de la Fiscalía General de Justicia, como institución representante de los intereses de la sociedad víctima del delito. La Asamblea Nacional, debe garantizar su independencia y autonomía.

Urge la reforma urgente e integral del Código Penal y Procesal penal. Hace falta, además, la creación de la Ley Penitenciaria y su Reglamento de Ejecución.

Todo lo anterior contribuirá al logro de una justicia penal más transparente, más equilibrada, menos selectiva y con menor impunidad.

\section{Bibliografía}

-BARATTA, A.(1997). "Política criminal: entre la política de seguridad y la política social", en Elías Carranza Delito y seguridad de los habitantes, Siglo XXI editores.

-CARRANZA, E. (1997). "Situación del delito y de la seguridad de los habitantes en los países de América Latina", en Elías Carranza Delito y seguridad de los habitantes, Siglo XXI editores.

-CARRANZA, E. (1994). Criminalidad. ¿Prevención o promoción?. San José. Editorial Universidad Estatal a Distancia.

-CUAREZMA, S. (1998). Código penal. Comentado y actualizado. Managua. Editorial Jurídica Hispamer.

-CUAREZMA, S. (1998). Código de instrucción criminal. Comentado, concordado y actualizado. Managua. Editorial Jurídica Hispamer.

-CUAREZMA, S. (1997)."Seguridad de los habitantes, adolescentes y ley penal", en Elías Carranza Delito y seguridad de los habitantes, Siglo XXI editores.

-Declaración final del seminario de reflexión científica sobre el delito y la seguridad de los habitantes (ILANUD, San José, Costa Rica, 9-13 de Octubre de 1995).

-LUZÓN, D. Curso de derecho penal. Managua. Editorial Jurídica Hispamer.

-SÁNCHEZ, C. (1992). La abolición del sistema penal. San José. Editec Editores S.A.

-SELK, R. (1997). Diagnóstico de la procuraduría general de justicia de la República de Nicaragua. Managua. National Center for State Courts/USAID.

-WALLER, I. (1997). "Prevención del delito: la nueva esperanza de las políticas de urbanismo", en Elías Carranza, Delito y seguridad de los habitantes, Siglo XXI editores.

-ZAPATA, R. (1997). "La perpectiva judicial del delito y la seguridad", en Elías Carranza Delito y seguridad de los habitantes, Siglo XXI editores. 